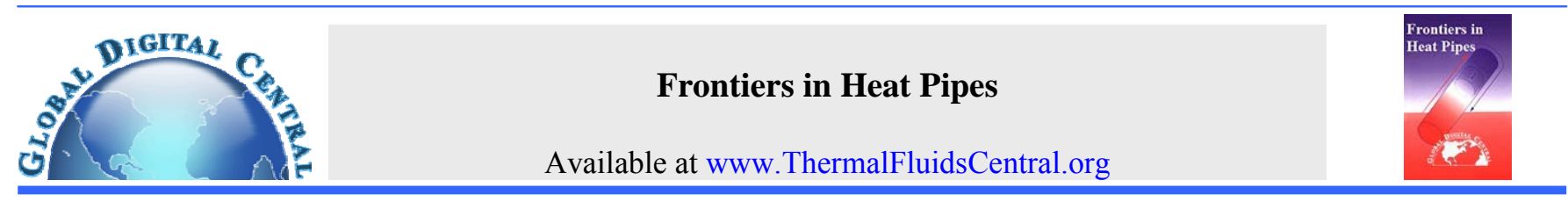

\title{
BENDABLE HEAT PIPES USING SINTERED METAL FELT WICKS
}

\author{
Dhananjay Dilip Odhekar ${ }^{\mathrm{a}}$, Daniel K Harris ${ }^{\mathrm{b}}$ \\ ${ }^{a}$ Quality Assurance Engineer, PTC, Needham, MA, 02494, USA \\ ${ }^{b}$ Department of Mechanical Engineering, Auburn University, Auburn, AL 36869, USA
}

\begin{abstract}
This work describes the effect bending within the adiabatic section has on the performance of heat pipes. The heat pipes described herein are bendable post fabrication and are distinct from heat pipes fabricated in bent configurations and from flexible heat pipes. The effect of bending on performance and performance limits was both calculated and measured. The heat pipes used for testing were the copper-water variety. The wick was made from sintered copper felt and provided the bendability feature of these heat pipes. The concept of copper equivalence to reduce performance measurements data was used via benchmark test data against solid copper pipes.

Keywords: Bendable, Conformal, Sintered Felt Wick.
\end{abstract}

\section{INTRODUCTION}

Heat transport has been one of the most difficult and inefficient tasks in thermal management. It often results in costly heat transfer losses and reduced overall efficiencies. Performance of mechanical and electronic components inside automobiles is now governed by the efficiency of cooling system (Kishimoto, 1994). Heat transfer by heat pipes is one of the fastest and most efficient methods for thermal management. In automobiles, the stress of modern design is on reducing bulk weight and volume of all components. This results in densely packaged components including drive trains and electronic components. The heat pipe is a promising technology that has received significant research interest since early 1950s. The early studies mostly concentrated on heat pipes used in straight configurations. But many practical designs demand heat pipes in contorted shapes (Shaoning and His-Shang, 1999). This work investigates the feasibility of bendable heat pipes using metal felts wicks made from sintered micro-fibrous metallic fibers. Heat pipes made using this class of wick can be bent up to $90^{\circ}$ after fabrication with minimal impact upon their performance. The basis of using micro-fibrous metal felt wicks in heat pipes is based upon Williams and Harris (2003), Williams and Harris (2005) and Odhekar (2005). This class of heat pipe can be bent into conformal shapes after fabrication and sealing. e.g. straight heat pipes of this variety can be acquired and integrated into systems requiring bended shapes in order to fit into contorted geometries. While bent heat pipes are readily available most are specially designed heat pipes with integrated bends designed a priori. This is a novel device in contrast to several other types of bendable and flexible heat pipes that have been found in the open literature over the last forty years.

\section{BACKGROUND}

Previous works cited focusing on flexible heat pipes including variable conductance heat pipes with bends and heat pipes fabricated with bends are summarized below. This review gives a brief historical account of the types of bendable and flexible heat pipes that have been reported and identifies some of the ideas and approaches that have been taken to achieve working heat pipes that have a bent geometry. A detailed survey of the performances and results of all the heat pipes cited would be too exhaustive and the interested reader is directed to Odhekar (2005).

\subsection{Flexible Heat Pipes}

A flexible heat pipe was developed and built by Bliss et al. (1970) to analyze its operating characteristics for varying degrees of bend and under vibration in an unbent mode. The purpose of this study was to design a flexible heat pipe capable of being bent or flexed during its operation allowing efficient heat transfer between an oscillating heat source and a stationary sink. The heat pipe was built using a rigid evaporator and condenser sections made from thick drawn copper tubing. A flexible adiabatic section fabricated from a seamless brass bellows connected them. A wick made of four layers of 150 mesh type 304 stainless steel screen, was held against the inside wall using a stainless steel coil spring. It was tested for bends of $0^{\circ}, 45^{\circ}$ and $90^{\circ}$ during horizontal operation and also at inclined orientations. The authors noted that the tests for various bends demonstrated an increase in the maximum heat flux associated with wick dry out after each flexing. It was speculated that this was due to the changes in the capillary passage between the layers of screen and wall as the heat pipe was flexed. One interesting aspect of this study was the internal fins present in the condenser section. It was noted that since the fins significantly reduced the difference between the vapor temperature and the outside temperature of the condenser wall, it had greatly improved the operating efficiency of the heat pipe. The study concluded that the degree of bending had a minimal effect on the working of the heat pipe and a flexible heat pipe is a feasible idea. Saaski and Wright (1975) described a proof of concept for a flexible cryogenic heat pipe designed for space operations. This heat pipe was meant for transmitting parasitic heat and generated heat from an infrared sensor on a satellite. In many satellite systems, a U shaped configuration of heat pipes was needed. A $20 \mathrm{~W}$ flexible heat pipe designed for operations at $100 \mathrm{~K}$ was described. The axial wick structure needed to be considerably flexible to allow bending. A multiple artery structure developed by McDonnell Douglas Astronautics Corporation (MDAC) was chosen due to its considerable capacity for bending. The artery was composed of a tightly wrapped bundle of many fine tubes, each of which functions independently as an artery to assure redundancy of fluid transport. The composite tube structure allowed for flexibility because each small tube could move independently to some degree. The evaporator and condenser were rigid sections connected by an adiabatic section made from bellows. Thermal performance tests were carried out with $\mathrm{R}-21$ at $293 \mathrm{~K}$ and methane at $100 \mathrm{~K}$ with the heat pipe in horizontal 
orientation and $U$ shape configuration. The test results for both straight and bent mode were compared and it was concluded that there was no significant effect due to bending. A comprehensive test program was executed to determine the physical and thermal performance of two flexible cryogenic heat pipes to provide an efficient and flexible thermal link between a detector and a space radiator by Wright et al. (1976). The wick selected was a multi wrap composite, which consisted of a spirally wrapped coarse mesh screen surrounded by a fine mesh outer wrap. V-groove screw threads were machined into the evaporator and condenser whereas a braided flexible bellows made from stainless steel was used for the adiabatic section. This flexible section together with the spiral multi wrap wick demonstrated good flexibility and compatibility with methane as the working fluid. The authors concluded that overall this configuration worked well as a highly flexible link between the source and the sink and had good potential for high power transport scenarios. Merrigan et al. (1984) demonstrated that flexible sodium/stainless steel heat pipes can be fabricated and operated at temperatures up to $1100 \mathrm{~K}$ with an axial heat flux of $1950 \mathrm{~W} / \mathrm{cm}^{2}$. There was a requirement for bending through angles of up to $180^{\circ}$ and working temperatures of both cold and high temperatures. A flexible heat pipe employing sodium as working fluid and using stainless steel wick and tube was fabricated and tested. A 100 mesh stainless steel screen wrapped in 3 layers in alternating directions was used to make the wick. The adiabatic section was made from a standard high vacuum flexible line section. The heat pipe was tested at a temperature of $1000 \mathrm{~K}$ in the horizontal orientation and tested with bends of $0^{\circ}, 90^{\circ}$ and $180^{\circ}$. While the data indicated a significant increase in axial temperature drop with bending there was no loss of heat pipe function due to bending even under test loads up to $1950 \mathrm{~W} / \mathrm{cm}^{2}$. Repeated startup tests were conducted from below the freezing point of sodium (working fluid) with no apparent effect due to bending. The authors concluded that this heat pipe could be bent up to $180^{\circ}$ even when under load. Shaubach and Gernert (1985) worked on a project to develop and demonstrate flexible heat pipes for transport of heat from stationary to translating sections of spacecraft. Previous flexible heat pipes concepts employed flexible bellows with a screen wick that allowed bending. Such heat pipes are typically low power devices due to the high flow resistance of the screen wick structure. Flexible heat pipes with high power capacity are made possible by using flexible screen arteries, which can be made from several different alloys and mesh sizes. These flexible screen arteries are integrated with high performance circumferential distribution wicks in an envelope that is flexible in the adiabatic section. Three heat pipes identical in all respects except that the wicks were built using screens, powder metal and spiral "V" grooves were tested. A flexible loop heat pipe cold plate was developed by N. J. Gernert and J. Brown (1995) which was very similar to the work done earlier by Gernert et al. (1991). The major difference is that this prototype operates in any orientation. It sustained a heat load of $45 \mathrm{~W}$ over a temperature drop of $20^{\circ} \mathrm{C}$. A flexible heat pipe cold plate technology was developed by Gernert et al. (1991) for aircraft thermal control. Four such heat pipes were built for a variety of difficult aircraft cooling situations. In each case, a cold plate transferred the source heat to the most convenient heat sink by an integrally connected flexible heat pipe. This permitted relative motion between the electronics package to be cooled and the heat sink and it also allowed cooling system access in awkward places. A method was suggested by Gus'kov et al. (1993) for calculating the thermal resistance and constraints on the load for an arterial flexible heat pipe working in cryogenic and low temperature modes. It permitted prediction of the heat pipe operation with various working fluids and different design variations; one such result for propylene heat pipe was presented. A report of joint activities of various Russian organizations aimed at the development of a flexible heat pipe and its modified version intended for thermal management of spacecraft instrumentation was presented by Zelenov et al. (1996). A flexible heat pipe increased reliability of units moving, folding and opening in space in addition to a reduction in power consumption of the thermal control system. Different heat pipes were developed as an outcome of experimental and theoretical studies of various configurations of the evaporator, condenser and adiabatic zones. It was shown that the principal performance characteristics of these pipes were comparable to other flexible heat pipes' performance. Quasi steady state operating characteristics of a flexible copper-water heat pipe were obtained experimentally by investigating its thermal performance under varying acceleration loading by Thomas and Yerkes $(1996,1997)$. Schweickart and M. M. Buchko (1998) discussed the design and testing of flexible heat pipes for space CCD camera applications. The flexible heat pipes used ammonia as working fluid and a rolled screen mesh wick supported by screen mesh web. As the flexible sections (made from flexible stainless steel hose) of the heat pipes were pre-formed after the wicks were inserted, additional bending of the flexible section posed little risk of wick damage. In an effort to build a flexible heat pipe that can provide for bending, twisting, oscillating and deforming that is typically required in compact electronics, Shaoning and His-Shang (1999) designed and built prototypes of a mini flexible heat pipe with a vacuum grade transparent plastic tube. The heat pipes were small in diameter, typically few millimeters, so as to accommodate mobile computers. New wick structures were designed to make internal twophase flow visible while providing the required capillary pumping action. The evaporator and condenser of the heat pipes were made of brass tubes and a transparent polyurethane tube was used for the flexible adiabatic transport section. Transparent wick structures were built from copper wire spring with a spring-braid wick and helical mesh stripe. This work discussed results from a spring wick heat pipe that made good contact with the heat pipe container and flexibility was maintained in any bent position. The spring was made from copper wire and water was used as working fluid. Ultra-highmolecular-weight (UHMW) film wicks and formed UHMW wicks with kapton and aluminized Mylar containers were used to design fabricate and test flexible heat pipes by Glass et al. (1999). The heat pipes used methanol as the working fluid and tests were carried out at steady state. From preliminary design studies it appeared that the design of a wick such that capillary and boiling limits are satisfied was the primary challenge. And finally, Ozaki et al. (2000) designed a bent aluminum looped heat pipe as a part of a graphite face skin panel on a deployable radiator panel.

\section{$2.2 \quad$ Flexible Variable Conductance Heat Pipes}

Edelstein (1975) designed and fabricated a variable conductance heat pipe radiator capable of passively controlling Freon-21 fluid loop temperatures under varying loads. It was made from six grooved heat pipes attached to an aluminum panel. The heat pipes had a flexible section that could bend up to $90^{\circ}$. Tests were carried out with radiator loads up to $800 \mathrm{~W}$. Three variable conductance heat pipes were fabricated by Peeples and Calhoun (1977) in order to investigate the effect of tight radius bends in the adiabatic section on the heat pipe performance. Analytical studies were conducted to evaluate the geometry and performance requirements of candidate heat pipe designs. The heat pipes were bent in the adiabatic section to make a $J$ or L shape with a very small bend radius. There was a probability that capillary pumping could be reduced due to deformation of internal structure in the bent area, resulting in performance degradation. Two pipes were fabricated from a thin wall stainless steel with a multi-tube central artery and a wall screen wick. Freon 21 was the working fluid. The third pipe was made of aluminum with an axially grooved wick and ammonia was used as the working fluid. All the pipes were bent using a conventional pipe bender and it was found that in the bend area the deformation of the artery lowered the permeability of artery, effectively reducing the heat transfer capacity of the pipe due to inadequate flow of condensate from condenser to evaporator. Corrugations in the inner bend surfaces of the heat pipe tube, and local separation of the wall wick caused unpredictable voids and it also made it difficult to determine the exact charge of the working fluid required. In order to circumvent these problems, the heat pipes were fabricated in such a way that the heat pipe tube was bent before inserting the wick structure and also wick in the bend area was removed to minimize cavities caused. Development work was undertaken for near room temperature applications of a thermal diode for Spacelab by M. Groll et al. (1978). The focus of this study was to predict the transient shutdown of the thermal diode using a mathematical model and experimental results, both of which were in good agreement. It was noted that bendability is no serious constraint 
for all three designs, though the bend radius had to be relatively large to avoid performance degradations. Mathieu et al. (1980) made a bendable gas controlled variable conductance heat pipe made entirely from stainless steel with ammonia as working fluid with a homogeneous wick as capillary system capable of $100 \mathrm{~W}$ through a 1 $\mathrm{cm}$ diameter tube curved in $\mathrm{U}$-shape with a radius of curvature of 10 $\mathrm{cm}$. Hwangbo and Joost (1988) developed a variable conductance heat pipe with a flexible joint for temperature control of high power electronics using a space radiator. The design requirements for this pipe mandated that a 0.5 " O.D. heat pipe should be able to sustain loads up to $3500 \mathrm{~W}$-inch at a vapor temperature of $80^{\circ} \mathrm{F}$. The design consisted of a sintered screen axial slab made by a 20 mesh screen sandwiched between two 100 meshscreens. This benefited from the increased permeability due to the 20 mesh screen as well as better capillary pumping by the 100 mesh screens.

\subsection{Heat Pipes with Bended Geometries}

Munzel et al. (1976) conducted an experiment for the European Space Research and Technology that consisted of two bendable artery heat pipes which were flown aboard a rocket Centre as a part of the International Heat Pipe Experiment. It consisted of two aluminum heat pipes having a length of about $90 \mathrm{~cm}$ with an outer diameter of $0.7 \mathrm{~cm}$. The wick and artery systems were made from 160 mesh stainless steel screen and ammonia was the intended working fluid. The two arteries were positioned to lie in the same diametric plane so that the pipes could be bent with no reduction in the heat transport capability. The experiment was supposed to test two heat pipes; one straight and one bent into a z-shape. The bent heat pipe was later replaced with a straight one due to priming problems. Meier et al. (1981) designed a heat pipe for use in a space reactor where it was required to bend around the reactor core in two approximately $90^{\circ}$ bends on a $180 \mathrm{~mm}$ radius and have design lifetime of 7 years. Because of this lifetime requirement and working temperature of $1400 \mathrm{~K}$, molybdenum was the material chosen for the container with sodium as the compatible working fluid. It employed a nonconcentric screen annular sintered wick. A bending test when conducted on an unsupported wick at $353 \mathrm{~K}$ that showed the compression side of the bent wick was severely buckled. The buckles caused a reduction of $17 \%$ in the vapor flow area and an increase in pore size was also observed at the sharp corners, which would lead to significant reduction in performance. The conclusion was that bending on an unsupported wick would not produce satisfactory results. Another bending test with a steel tube mandrel to prevent buckling of the wick was performed, but large tears were generated on the tension side. Finally, a stainless steel heat pipe was completely filled with sodium at $1070 \mathrm{~K}$. When the pipe was bent at $365 \mathrm{~K}$ (highest attainable temperature to provide required ductility for molybdenum but still low enough to keep the sodium mandrel in solid state), the results were successful with no tears in the tension side and very little buckling on the compression side with a very minute change in porosity. Ernst (1981) demonstrated the validity of several complicated geometries and wick structures including bends in the heat pipe. Two types of heat pipes with $30^{\circ}$ bends at each end of the adiabatic section were tested for several wick designs. A heat pipe with four wraps of 325 mesh wick was found as a good design with respect to performance and mass. It transferred $3800 \mathrm{~W}$ over a temperature drop of $117.9^{\circ} \mathrm{C}$.

\section{BENDABLE WICKS}

Only certain types of wicks can be used in bendable heat pipes. And wick will have a tendency to separate from the container walls under bending. This separation has two adverse effects, a reduction in the vapor core area that reduces heat transfer capacity and a disruption in the path of liquid flowing back to the evaporator. If the bending angle is severe, the wick can crumple (Peeples and Calhoun, 1977) and even tear off in extreme cases. The sintered copper felt wick provides a very flexible wick material that does not crack after bending as well. However, a wick made from sintered metal powder will crack under bending. Although other wicks made from metal screens may also work with supporting springs, this work is a continuation of ongoing work on metal felt heat pipes at Auburn University (Vadgama, 2004). The heat pipe was bent in only one location to reduce the complexities in testing. After successful tests on such heat pipes further studies on multiple bends could be carried out. Several bending angles $\left(15^{\circ}, 30^{\circ}, 45^{\circ}, 60^{\circ}\right.$ and $\left.90^{\circ}\right)$ with a constant bending radius of $18.18 \mathrm{~mm}$ (pipe axis) were tested. A series of photographs of the heat pipe cross section after bending were taken for various bent configurations and expectedly separation of wick was observed. However, it was noted (Fig. 1) that the separation from the wall slowed down after $45^{\circ}$. Also a $90^{\circ}$ bend was cut and, it was observed that the wick was not damaged due to stretching and crumpling at outer and inner walls as shown in Fig. 1 (a) \& (b). It can be seen in Fig.1 (c)-(e) that the inner and outer walls of the curved part of the heat pipe had deformed due to crumpling and stretching respectively. The working fluid gets trapped in the gaps created by the separation of the wick from the container walls. This film of working fluid has a lower conductivity as compared to that of the wick and it reduces the heat transfer to the heat pipe. Therefore, deformation is acceptable only in the adiabatic section and not in the condenser section and the evaporator section.

\subsection{Capillary limit}

The expression for capillary limit given by Faghri (1995) is a follows,

$\frac{2 \sigma}{r_{e f f}}=\left(\frac{\mu_{l}}{K A_{w} \rho_{l} h_{f g}}+\frac{\left(f R e_{z}\right) \mu_{v}}{2 R_{v}^{2} A_{v} \rho_{v} h_{f g}}\right) Q_{e} L_{e f f} \pm \rho_{l} g L_{t} \sin \phi$

where the liquid and vapor frictional coefficients are respectively defined as follows.

$F_{l}=\frac{\mu_{l}}{K A_{w} \rho_{l} h_{f g}} F_{v}=\frac{\left(f R e_{z}\right) \mu_{v}}{2 R_{v}^{2} A_{v} \rho_{v} h_{f g}}$

Therefore, the capillary heat input limit is given by the following expression.

$Q_{c a p}=\frac{\frac{2 \sigma}{r_{e f f}} \pm \rho_{l} g L_{t} \cos \phi-\rho_{l} g D_{v} \sin \phi}{L_{e f f}\left(F_{l}+F_{v}\right)}$

This is the base relation for a straight cylindrical heat pipe that has an inclination angle with respect to the gravitational vertical. It should be noted that since this heat pipe uses a wick, which allows circumferential communication of liquid, the normal hydrostatic pressure drop term has to be accounted for in the capillary limit (Peterson, 1994). When the heat pipe is in the horizontal position and the axial pressure drop is eliminated, the capillary limit can be reduced to the following expression.

$Q_{\text {cap }, \text { horizontal }}=\frac{\frac{2 \sigma}{r_{e f f}}-\rho_{l} g D_{v}}{L_{e f f}\left(F_{l}+F_{v}\right)}$

Similarly in the vertical orientation where the inclination is zero and there is no normal pressure drop term, the expression becomes

$Q_{\text {cap, verical }}=\frac{\frac{2 \sigma}{r_{e f f}} \pm \rho_{l} g L_{t}}{L_{e f f}\left(F_{l}+F_{v}\right)}$

When the heat pipe is in gravity assisted mode of operation, the axial pressure drop term is positive in Equation (5) otherwise when the evaporator is on the top and the heat pipe is working against the gravity, it has a negative sign.

\subsection{Bend Loss}

When a pipe is bended, there is an additional pressure drop caused primarily due to result of secondary flow and is usually represented by an equivalent length of a straight pipe (Fox and McDonald, 1985). The secondary flows are rotating motion, normal to the pipe axis and are superimposed on the main flow in the direction of the axis. The friction at the pipe walls and the centrifugal force combine to produce these rotations (Crane Technical Paper, 1982). The bend loss can be 
accounted for as a function of dynamic pressure of the vapor. Most of the available data in the literature relate this loss to the relative radius of the curvature, or the Dean Number, De and account for the bend angle in terms of the length of the curvature. Crane Technical Paper (1982) provides a relation for calculating bend loss coefficients, $K_{b}$. The relation provided is for turbulent flows in bends of $90^{\circ}$. The work available on laminar flow is very limited and the only reported study included experimental results for a loss factor $\mathrm{K}_{\mathrm{b}}$ as a function of the Reynolds number (Powle, 1981). The data is available for some limited radii ratios of $4.52,6.08,13.06$ and 23.42 . The data indicates that as the Reynolds number increases the friction factor for the bend decreases. Ito (1969) and Misra et al. (1997) have published results of their work on the laminar flows in curved pipes. Both produced similar relations for the relative friction factor of a curved pipe in terms of the Dean number. For laminar flow through a bend angle of $\phi$, the bend loss was reported as the sum of the pressure drops due to bend and frictional pressure drops in a straight pipe of an equivalent length. Using these concepts the capillary limits for bent heat pipes for the three nominal gravity orientations are given in Faghri (1995) as follows.

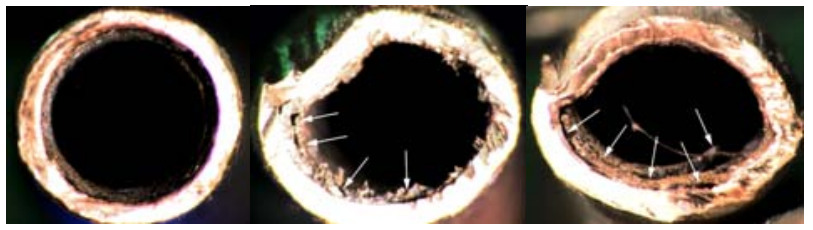

(a) Straight

(b) $15^{\circ}$

(c) $30^{\circ}$

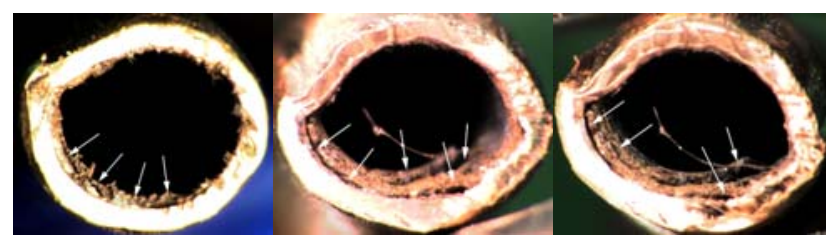

(d) $45^{\circ}$

(e) $60^{\circ}$

(f) $90^{\circ}$

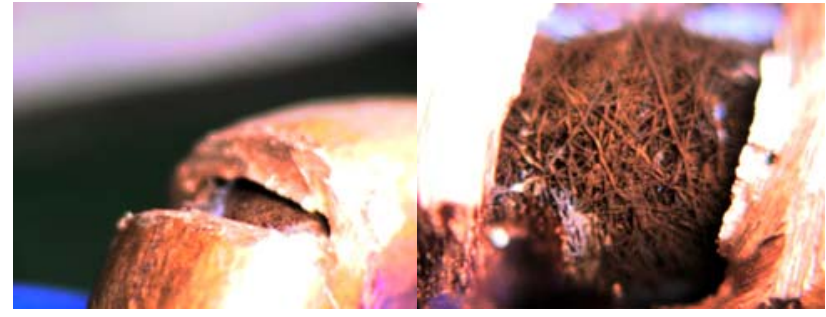

(g) external view of wick at bend locations

Fig. 1 Bending effects on heat pipe wick at10X magnification. Horizontal orientation

$Q_{c a p, h o r i z o n t a l}=\frac{\frac{2 \sigma}{r_{e f f}}-\rho_{l} g D_{v}-\left(K \frac{Q_{e}^{2}}{2 \rho A_{v}^{2} h_{f g}^{2}}\right)}{L_{e f f}\left(F_{l}+F_{v}\right)}$

Vertical gravity assist orientation

$Q_{\text {cap, }, \text { verical, } \text { gravity }}=\frac{\frac{2 \sigma}{r_{e f f}}+\rho_{l} g \frac{L_{t}}{2}(1+\cos \phi)-\rho_{l} g D_{v} \sin \phi-\left(K \frac{Q_{e}^{2}}{2 \rho A_{v}^{2} h_{f g}^{2}}\right)}{L_{e f f}\left(F_{l}+F_{v}\right)}$

Vertical gravity adverse orientation

$Q_{\text {cap, vertical ,adverse }}=\frac{\frac{2 \sigma}{r_{e f f}}-\rho_{l} g \frac{L_{t}}{2}(1+\cos \phi)-\rho_{l} g D_{v} \sin \phi-\left(K \frac{Q_{e}^{2}}{2 \rho A_{v}^{2} h_{f g}^{2}}\right)}{L_{e f f}\left(F_{l}+F_{v}\right)}$
All tests completed and reported herein were preformed under the capillary limit and bent pipe performance values were derived without experiencing capillary failure. Therefore, the capillary limit for bent heat pipes were needed to ensure any failure experienced would not be accounted from usual operating limit failure mechanisms. Using Equations (6), (7), and (8) the capillary failure limits were computed to identify the expected influence bends in the adiabatic section will have on the capillary limit. The results of these computations are shown in Fig. 2 for HP01 fabricated and tested under this study. The heat pipe design parameters are defined in Table 1 in Section 4. From these charts it is evident that as the bending angle increases, the capillary limit decreases, mainly due to the decrease in the axial hydrostatic pressure drop. The loss due to the bending itself was not significant and is almost negligible compared to the loss in the axial hydrostatic pressure drop.

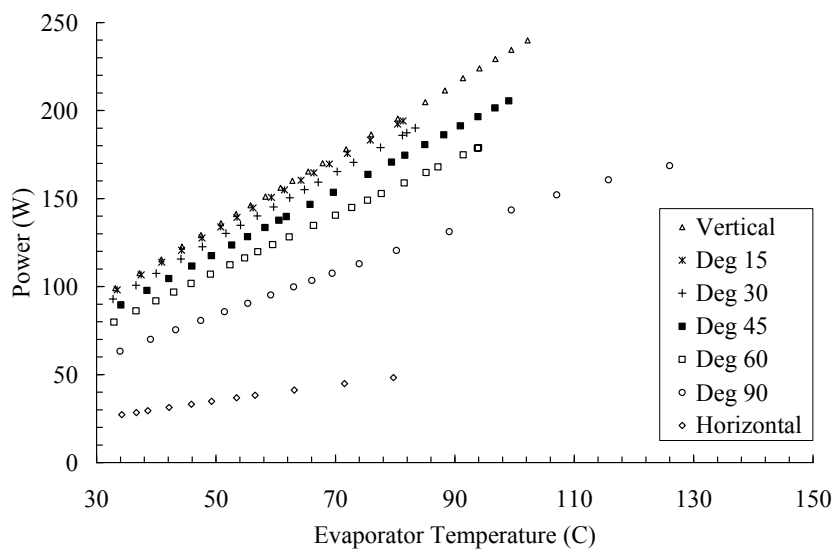

Fig. 2 Effect of bending angle on capillary limit for HP01

\subsection{Other limits}

In addition to the capillary limit other performance limits were also calculated to check if they could be responsible for heat pipe failure. The relations required for these limits were used from available literature (Faghri 1995 and Peterson 1994) and are listed below for reference purposes.

Sonic Limit

$Q_{\text {sonic }}=0.474 A_{v} \rho_{v} h_{f g}\left[\frac{\gamma_{v} R_{v} T_{0}}{2\left(\gamma_{v}+1\right)}\right]^{\frac{1}{2}}$

Entrainment Limit

$Q_{\text {entrainment }}=A_{v} h_{f g}\left[\frac{\sigma \rho_{v}}{2 R_{h, w}}\right]^{\frac{1}{2}}$

Boiling Limit

$Q_{\text {boiling }}=\frac{2 \pi L_{e} k_{e f f} T_{v}}{h_{f g} \rho_{v} \ln \left(r_{i} / r_{v}\right)}\left(\frac{2 \sigma}{r_{n}}-\Delta p_{c a p, \max }\right)$

As can be seen in the Equations (9), (10), and (11) the only influence a bend in the adiabatic section imposes on these heat pipe limits is in the appearance of the vapor pressure term. These failure mechanisms were not studied directly but avoided. In all testing reported here theses limits were calculated to ensure that the first failure mode experienced by the heat pipes being tested would be the capillary limit.

\section{PERFORMANCE TESTING}

Two heat pipes were fabricated and tested for studying the concept of bendable heat pipes using micro-fibrous felt wicks. The duplicate heat pipes were both tested separately to ensure repeatability of the recorded measurements. The heat pipes tested consisted of a wick made from the sintered copper felt with water as the working fluid. The design parameters for both heat pipes fabricated are shown 
below in Table 1 where a blank value under the HP02 column indicates an identical value to HP01.

Table 1 Heat pipe design parameters

\begin{tabular}{|l|c|c|}
\hline \multicolumn{1}{|c|}{ Design Parameter } & HP01 & HP02 \\
\hline Container outer diameter $(\mathrm{mm}) \mathrm{D}$ & 6.35 & \\
\hline Working length $(\mathrm{mm}) \mathrm{L}$ & 276.2 & 274.1 \\
\hline Evaporator length $(\mathrm{mm}) \mathrm{L}_{\mathrm{e}}$ & 38.1 & 25.4 \\
\hline Condenser length $(\mathrm{mm}) \mathrm{L}_{\mathrm{c}}$ & 38.1 & 48.65 \\
\hline Adiabatic section length $(\mathrm{mm}) \mathrm{L}_{\mathrm{a}}$ & 200 & \\
\hline Sintered metal felt wick thickness $(\mathrm{mm})$ & 0.3175 & \\
\hline Porosity $(\varphi)$ & $87 \%$ & \\
\hline Length of metal felt strands $(\mathrm{mm})$ & 10 & \\
\hline Diameter of metal felt strands $(\mathrm{mm})$ & 0.035 & \\
\hline Charge $(\mathrm{g})$ & 1.3 & 1.26 \\
\hline Permeability $\left(\mu \mathrm{m}^{2}\right)$ & 442.76 & \\
\hline
\end{tabular}

\subsection{Test Setup}

The first set of tests were carried out on HP01 and included testing in horizontal, vertical gravity assisted and bended in the vertical gravity assist orientation for the angles of $15^{\circ}, 30^{\circ}, 45^{\circ}, 60^{\circ}$ and $90^{\circ}$ with a constant bending radius of $18.18 \mathrm{~mm}$. For HP02, additional tests were carried out for bended heat pipes in both the horizontal and the adverse gravity orientation for the same series of angles. This allowed for the elimination of the effects caused by the axial hydrostatic pressure drop. The axial hydrostatic pressure drop is a significant component in the total capillary pumping pressure in the vertical gravity assisted position. Testing in the horizontal and vertical adverse gravity orientation meant that the heat pipe was working solely on the capillary pumping pressure. A schematic of test setup is shown in Fig. 3

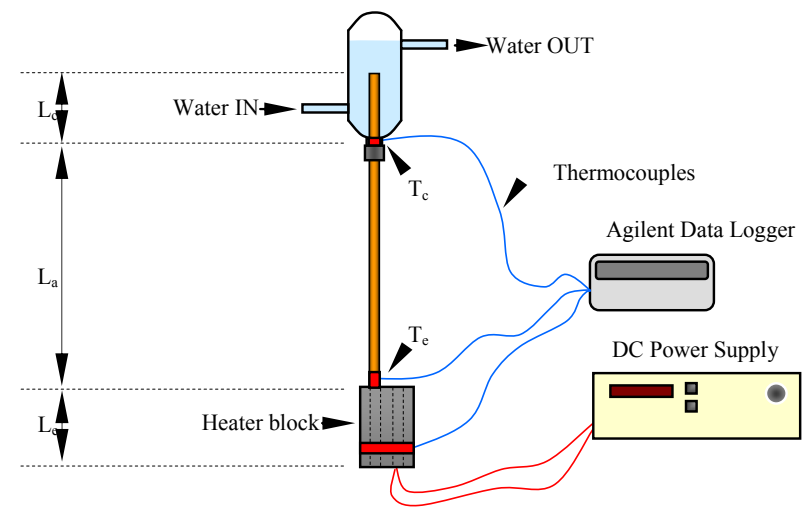

Fig. 3 Experimental test setup for pipe conductance measurements

The testing procedure devised was based on the principle of measuring the effective copper equivalence. The heat pipe was subjected to a heat load across its working length. The evaporator is connected to a heat source, typically a heater block. This heater block was powered by cartridge heaters whose power input was controlled by a regulated power supply. Heat was extracted from the condenser end by a water circulator that has a supply of constant temperature water from a chiller. A record of temperatures at different power levels was kept using two type-K thermocouples mounted on the evaporator and condenser ends as indicated. The chiller was started first and allowed to attain a steady $20^{\circ} \mathrm{C}$ bath temperature. The heat pipe was also allowed to attain a steady state temperature of $20^{\circ} \mathrm{C}$ to assure a common starting point for all the tests performed. The power was then supplied to the heater in uniform increments and the heat pipe temperatures were observed until steady state was reached and maintained for at least fifteen minutes. The ambient temperature was maintained between $20-23^{\circ} \mathrm{C}$ to keep the parasitic losses at approximately the same levels for all tests. A sample graph is shown in Fig. 4 showing the uncertainty bars. At this point, a note of all the readings was taken and used for further analysis.

\subsubsection{Conductance}

The temperatures of the evaporator and condenser at steady state were recorded and a temperature gradient was calculated. With the known power input, the heat pipe's performance at that load was measured in terms of conductance $\mathrm{G}$ as defined below,

$G=\frac{Q}{\Delta T}=\frac{k \cdot A}{L}$

The unit of conductance is $\mathrm{W} /{ }^{\circ} \mathrm{C}$ or $\mathrm{W} / \mathrm{K}$. Thus for a heat pipe with a steady state heat load of $12 \mathrm{~W}$ and $\Delta \mathrm{T}$ of $0.72^{\circ} \mathrm{C}$ the conductance was $16.8 \mathrm{~W} / \mathrm{K}$. The heat pipe performance was then plotted as a graph of conductance against input power. The parasitic losses of the test setup were measured and all input powers reported were corrected using this calibration. The effect of this correction is shown in Fig. 5.

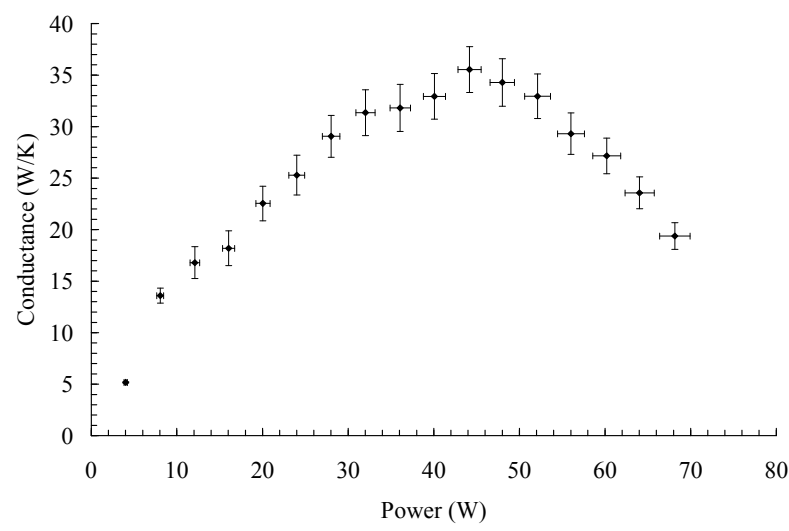

Fig. 4 Heat pipe conductance versus power showing uncertainty bars

\subsubsection{Copper Equivalence}

As mentioned above, this measurement technique used in this study accounted for and eliminated systematic measurement errors by comparing all heat pipe conductance measurements to the measurements using a solid copper sample of the same dimensions in the same test setup. The reduced thermal conductivity was expressed in the form of thermal conductance. The effective copper equivalence was then reduced by comparing the performance measurements under identical loadings to report the heat pipe conductance However, unlike a solid, the heat pipe's conductivity depends on many factors due to the complexity of two phase heat transfer and flow that occurs inside the heat pipe. The location of temperature measurement chosen during testing is a major factor influencing the thermal conductivity reported. Therefore, care was taken to place the evaporator and condenser thermocouples in the exact identical locations that were used during the solid copper rod testing.

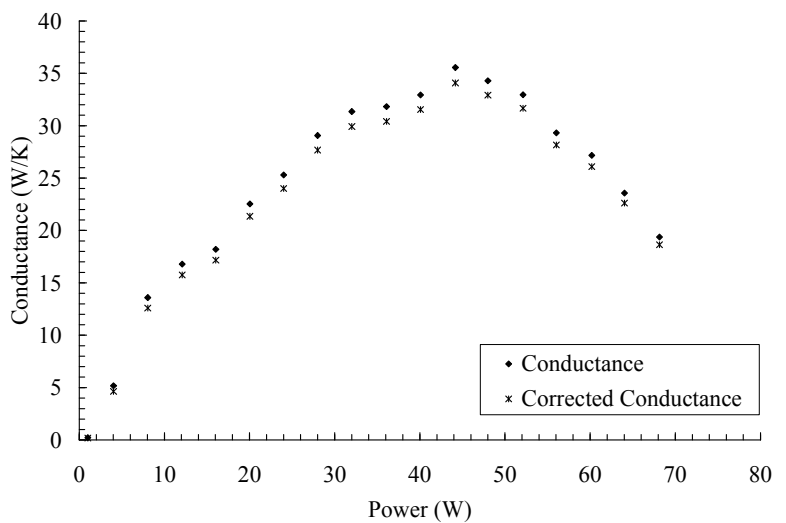

Fig. 5 Heat pipe conductance versus power after parasitic loss correction 


\section{RESULTS \& DISCUSSION}

The following sections show the results from testing both heat pipes for various bending angles. The results are presented in the graphical format in Figs. 6 through 12 due to the large number of readings for each test. The charts are included for input power against copper equivalence for following cases: straight horizontal and vertical, $15^{\circ}$, $30^{\circ}, 45^{\circ}, 60^{\circ}$, and $90^{\circ}$ bent vertical. Where vertical refers to gravity assisted operation. It was noticed that in all tests the copper equivalence showed a similar trend. A bell shaped curve was observed for all tests. As the power was increased, the copper equivalence went up till it reached a maximum value and then it came down. The tests were repeated two and four times for each heat pipe respectively to mitigate measurement scatter uncertainties. All the results are shown in terms of the copper equivalence. e.g. the conductance of a solid copper rod with a circular cross section of $0.635 \mathrm{~cm}$ diameter and a length of $23.8 \mathrm{~cm}$ is $0.0532 \mathrm{~W} /{ }^{\circ} \mathrm{C}$. However, the measured conductance was compared to the measured performance of a solid copper rod in the same test stand. The measured heat pipe conductance was then divided by the measured solid copper rod conductance, giving the copper equivalence.

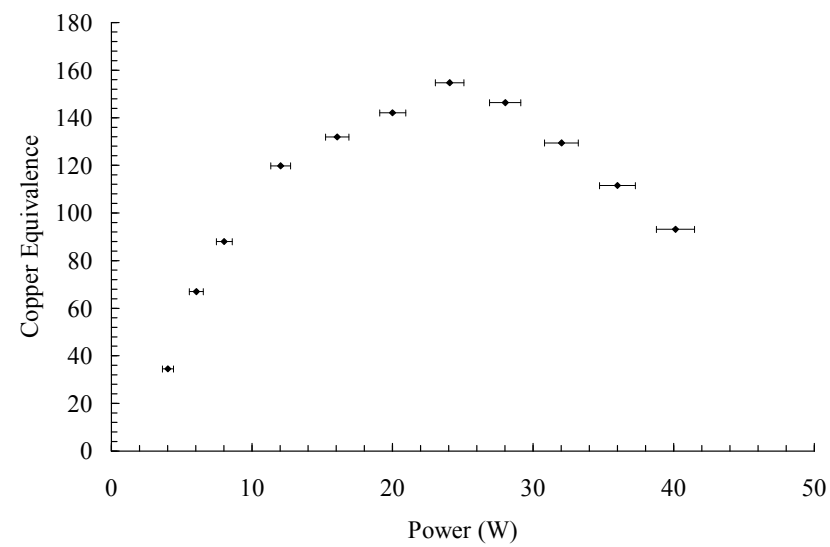

Fig. 6 Test results - straight horizontal position

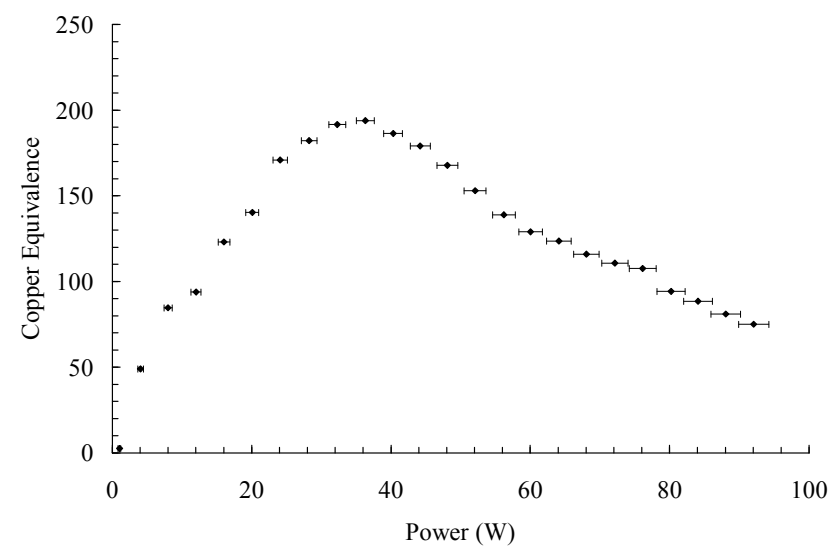

Fig. 7 Test results - straight vertical gravity-assist orientation

The results show that the bending loss was negligible and the capillary limit was mostly affected by the gravitational pressure drop. Hence the capillary limit variation for the horizontal orientation was not shown since all values overlap. The increasing bending angle drove down the conductance values of the heat pipe. This was due to the rise in the temperature difference along the heat pipe length. As previously reported by Merrigan et al. (1984), the axial temperature drop showed an increasing trend with increasing bending angle and did not significantly affect the operation of the heat pipe. During testing it was noted that the time required for attaining steady state at higher power levels doubled to approximately 60-90 minutes from a normal time of $30-40$ minutes.

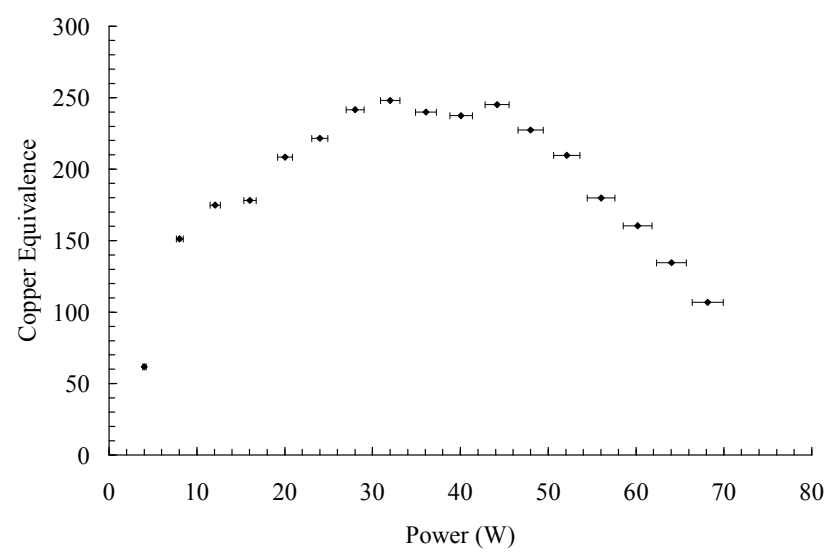

Fig. 8 Test results $-15^{\circ}$ vertical gravity-assist orientation

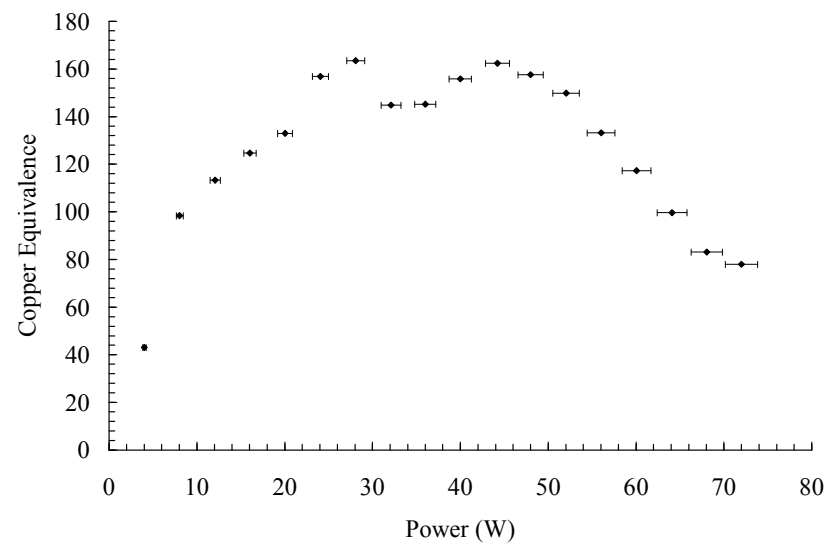

Fig. 9 Test results $-30^{\circ}$ vertical gravity-assist orientation

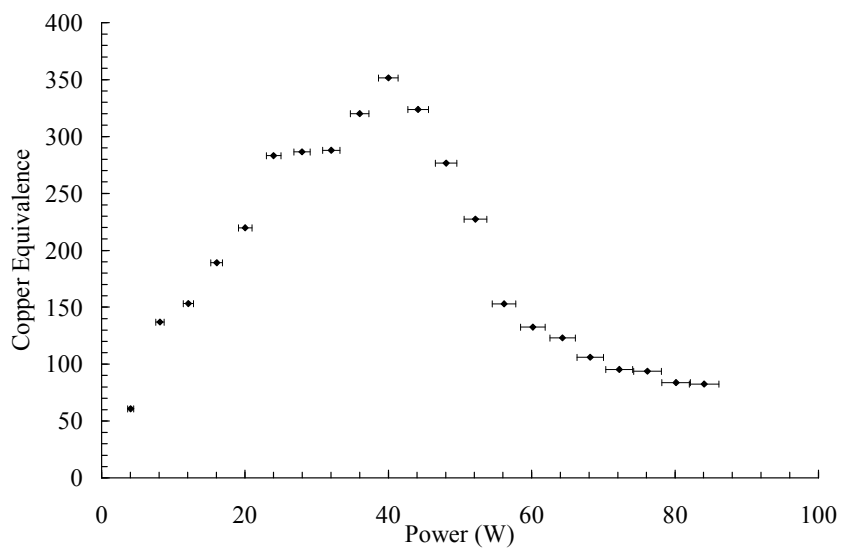

Fig. 10 Test results $-45^{\circ}$ vertical gravity-assist orientation

It can be seen that the capillary limits calculated using the test data were higher than the input power for most of the tests carried out. When the heat pipe was in horizontal orientation the axial gravitational pressure drop was absent, capillary pumping pressure was the only driving factor. Therefore, all tests in horizontal orientation show a trend towards the capillary limit curve. Therefore, the possibility of encountering capillary limit in horizontal orientation was low. Additionally, since the boiling limit is a radial flux limitation, it was found that the heat pipe was limited by boiling phenomenon in situations where the capillary limit was high and the operating temperatures and input heat flux were high enough to initiate nucleate boiling. Care was taken not to encounter this failure 
mechanism during testing. Finally, calculations of energy losses in the bended section of the heat pipe, found that it was very low and practically incapable of influencing the capillary limit. This can be explained by considering the Reynolds numbers for the vapor flow. The vapor flow was laminar for all the tests and Reynolds number was in the range of 10-900. The low density and the high viscosity minimized the expected losses due to centrifugal forces at the bend and hence the frictional pressure drop was negligible. The bending losses increased at higher powers as the Reynolds number increased due to the increased vapor density.

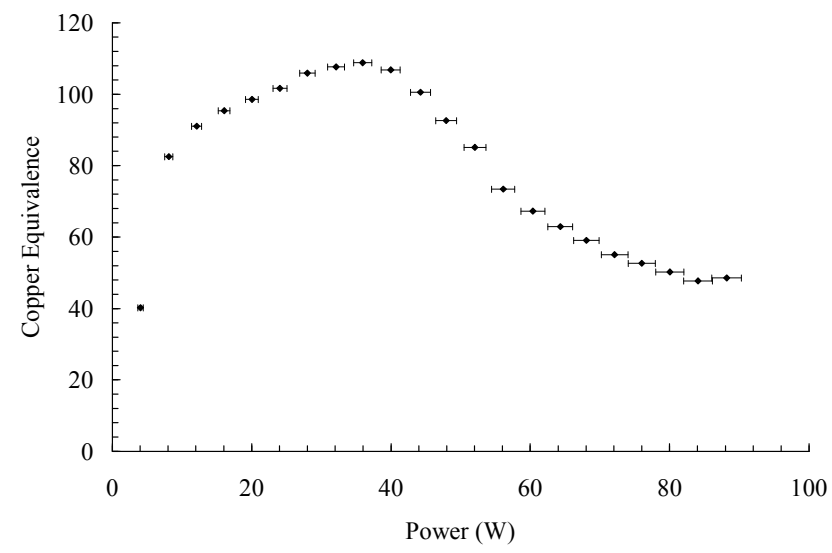

Fig. 11 Test results $-60^{\circ}$ vertical gravity-assist orientation

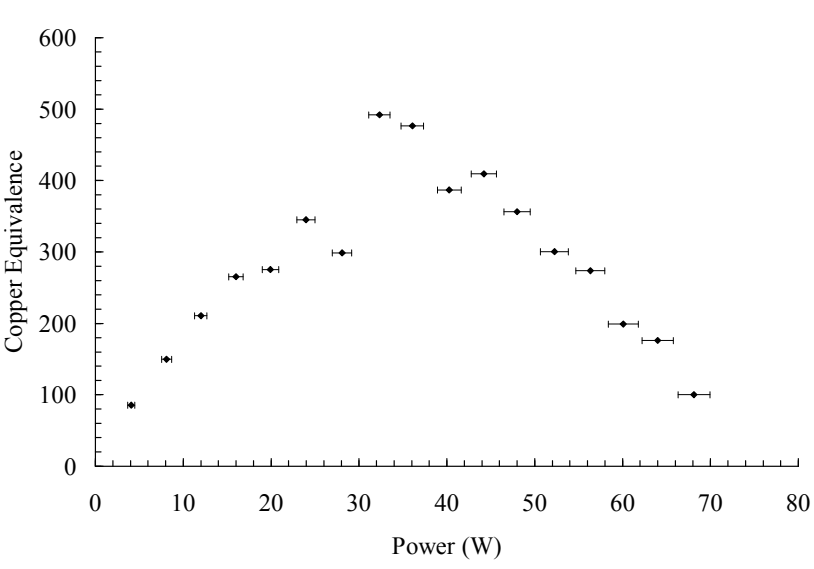

Fig. 12 Test results $-90^{\circ}$ vertical gravity-assist orientation

\section{CONCLUSIONS}

Two copper water heat pipes using sintered copper felt as the wick were fabricated and tested to demonstrate the feasibility of bendable heat pipes through the use of sintered metal felt wicks. A thorough literature review showed that flexible heat pipes have attracted a lot of attention over the years. But all of the work published previously was geared towards making pipes which were either flexible or bent a-priori during fabrication. It was found that no attempt was made to explore the possibility of stock heat pipes which can be bent or flexed in different shapes as required by the target application.

The ongoing work on heat pipes made using sintered copper felt as the wicking medium was extended to explore this possibility. The results for bendable heat pipes are encouraging as the heat pipe was found to work well in all orientations and up to a bend of $90^{\circ}$. The effect of pressure loss due to bending was found to be negligible and three to four orders of magnitude smaller than the capillary pumping pressure. This shows that the increase in the temperature drop due to bending is because of the obstruction in the flow of liquid returning

to the evaporator from the condenser. The investigation of wick separation due to bending showed a noticeable separation of the wick from the container walls. The vapor flow area was also reduced that directly reduced the heat carrying capacity. This lead to the buildup of temperature at the evaporator end at constant heat input. The performance in adverse orientation was observed to increase with increasing bending angle, which is expected as the axial hydrostatic pressure drop decreased with half of the heat pipe eventually being oriented horizontally after the $90^{\circ}$ bend. The benchmarking method used for comparing different heat pipes, which is designated as Copper Equivalence, was used to report heat pipe performance. The possibility of multiple bends needs to be explored for this concept to be feasible in practice. The current heat pipes were found to be capable of working after multiple bends although no systematic testing was carried out. The possibility of the heat pipe working beyond $90^{\circ}$ could also be explored. Even though such studies have been published in the past, post-fabrication bending was never investigated for these cases. The effect of relative radius of curvature on the heat pipe performance needs further investigation. Finally, wick separation studies could be performed for possible remedies including spring or mandrel supports during bending.

\section{NOMENCLATURE}

$A$
$\mathrm{D}$
$\mathrm{F}$
$f$
$\mathrm{G}$
$\mathrm{g}$
$h_{f g}$
$k$
$\mathrm{~K}$
$\mathrm{~L}$
$Q$
Re
$R$
$\mathrm{R}_{h, w}$
$r$
$T$

Greek Symbols
$\Delta$
$\gamma$
$\mu$
$\rho$
$\sigma$

Subscripts

a boiling

c

cap

e

i

entrainment

eff

$l$

$\mathrm{n}$

$o$

sonic

$\mathrm{t}$

W

$v$ area $\left(\mathrm{m}^{2}\right)$

diameter $(\mathrm{m})$

friction coefficient

Darcy friction factor

conductance $(\mathrm{W} / \mathrm{K})$

gravitational constant $\left(\mathrm{m} / \mathrm{s}^{2}\right)$

enthalpy of vaporization $(\mathrm{J} / \mathrm{kg}-\mathrm{K})$

thermal conductivity $(\mathrm{W} / \mathrm{m}-\mathrm{K})$

permeability $\left(\mathrm{m}^{2}\right)$

length $(\mathrm{m})$

limiting heat load or heat (W)

Reynolds number

gas constant $(\mathrm{J} / \mathrm{mol}-\mathrm{K})$

hydraulic radius of the wick surface for entrainment limit

radius $(\mathrm{m})$ or pore size $(\mathrm{m})$

temperature $(\mathrm{K})$

difference

ratio of specific heats

dynamic viscosity ( $\mathrm{kg} / \mathrm{m}-\mathrm{s})$

density $\left(\mathrm{kg} / \mathrm{m}^{3}\right)$

surface tension $(\mathrm{N} / \mathrm{m})$

angle off gravity normal

adiabatic section

boiling limit

condenser region

capillary limit

evaporator region

inner radius of the pipe wall

entrainment limit

effective

liquid

nucleation site radius

rest or initial value

sonic limit

total length of heat pipe

wall

vapor (or vapor space radius for boiling limit)

ambient environment 


\section{REFERENCES}

Bliss Jr., F. E., Clark Jr., E. G., and Stein, B., 1970, "Construction and test of a flexible heat pipe," ASME Conference Paper, 70$\mathrm{HT} / \mathrm{SpT}-13$.

Crane Company 1982, "Flow of Fluids through Valves, Fittings and Pipe," New York, N.Y., Technical Paper No. 410. ISBN 1-40052712-0

Edelstein, F., 1975, "Deployable heat pipe radiator [Final Report]," NASA Report.

Ernst D. M., 1981, "Heat pipe heat rejection system and demonstration model for the nuclear electric propulsion (NEP) spacecraft [Final Report]," NASA Report.

Faghri A., 1995, Heat Pipe Science and Technology. Washington, D.C., Taylor \& Francis. ISBN 1-56032-383-3

Fox, R. W. and McDonald, A. T., 1985, Introduction to Fluid Mechanics, John Wiley \& Sons, Inc. ISBN 978-0-470-54755-7

Gernert, N., Sarraf, D., and Steinberg, M., 1991, "Flexible heat pipe cold plates for aircraft thermal control," SAE Aerospace Technology Conference and Exposition, Long Beach, CA.

Gernert, N. J. and Brown, J., 1995, "Development of a flexible loop heat pipe cold plate," SAE Aerospace Atlantic Conference, Dayton, $\mathrm{OH}$.

Groll, M., Muenzel, W. D., Supper, W. and Savage, C. J., 1978, "Development of an axial groove aluminum-ammonia liquid trap heat pipe thermal diode," 3rd International Heat Pipe Conference, Palo Alto, $C A$.

Gus'kov, A. S., Gortyshov, Y. F., and Poskonin, Y. A., 1993, "Calculation of the thermophysical characteristics of an arterial flexible heat pipe," Izvestiya Vysshikh Uchebnykh Zavedenij. Aviatsionnaya Tekhnika, 4:38-43.

Hwangbo, H. A. N. and Joost, T. E., 1988, "A flexible variable conductance heat pipe design for temperature control of spacecraft equipment," AIAA Thermophysics, Plasmadynamics and Lasers Conference, San Antonio, TX.

Ito, T H., 1969, "Laminar flow in Curved Pipes," Z. Angew. Math. Mech, 49:653-656.

http://dx.doi.org/10.1002/zamm.19690491104

Incropera, F. P. and DeWitt, D. P., 1985, Introduction to Heat Transfer, John Wiley \& Sons, Inc. ISBN 978-0-471-45728-2

Mathieu, J. P., Moschetti, B. and Savage, C. J., 1980, "Development of a high performance variable conductance heat pipe," AIAA 15th Thermophysics Conference, Snowmass.

Meier, K. L., Martinez, H. E. and Runyan, J. E., 1981, "Development of space reactor core heat pipes," Intersociety Energy Conversion Engineering Conference, Atlanta, GA.

Merrigan, M. A., Keddy, E. S., Sena, J. T. and Elder, M. G., 1984, "Heat pipe technology development for high temperature space radiator applications," Proceedings of the 19th Intersociety Energy Conversion Conference, LaGrange Park, IL.

Misra, J. C., Patra, M. K. and Misra, S. C., 1997, "Laminar boundary-layer flow of a Newtonian fluid through a curved pipe some applications to arterial flow dynamics," International Journal of Engineering Science, 32 (12):1997-2010.

http://dx.doi.org/10.1016/0020-7225(94)90095-7

Muenzel, W. D., Savage, C. J., Accensi, A. and Aalders, B. G. M., 1976, "Performance evaluation of the ESRO heat pipes included in the International Heat Pipe Experiment (IHPE) (using ammonia and acetone as working fluids)," European Space Agency Report.
Odhekar, D. D., 2005, Experimental Investigation of Bendable Heat Pipes, M.S. Thesis, Auburn University, Auburn, AL

Ozaki, T., Yao, A., Ohkawa, Y., Seko, H., Tsujihata, A. and Noda, H., 2000, "Graphite faceskin deployable radiator panels for space satellites," Proceedings of the 45th International SAMPE Symposium and Exhibition, Long Beach, pp.1944-1953.

Peeples, M. E. and Calhoun, L. D., 1977, "Fabrication and comparative performance of three variable conductance heat pipe concepts," ASME Paper.

Peterson, G. P., 1994, An Introduction to Heat Pipes - Modeling, Testing and Applications, John Wiley \& Sons, Inc. ISBN 0-47130512-X

Powle, U. A., 1981, "Energy losses in smooth pipe bends," Mechanical Engineering Bulletin, 12(4):104-109.

Saaski, E. W. and Wright, J. P., 1975, "A flexible cryogenic heat pipe," AIAA 10th Thermophysics Conference, Denver, CO.

Schweickart, R. B. and Buchko, M. M., 1998, "Flexible heat pipes for CCD cooling on the Advanced Camera for Surveys," Proceedings of the 5th Space Telescopes and Instruments, pp. 292-300, Kona.

Shaoning Lu and His-Shang Li, 1999, "Oscillatory mode with extremely high heat transfer rate in a flexible heat pipe," InterPACK '99: Pacific RIM/ASME International Intersociety Electronics Photonic Packaging Conference 'Advances in Electronic Packaging', Maui, HI.

Shaubach, R. M. and Gernert, N. J., 1985, "High performance flexible heat pipes," AIAA 20th Thermophysics Conference, Williamsburg, VA.

Thomas, S. K. and Yerkes, K. L., 1996, "Quasi-steady state thermal resistance of a flexible copper-water heat pipe subjected to transient acceleration loading," Proceedings of the 31st Heat Transfer Conference, pp. 349-356, Houston.

Thomas, S. K. and Yerkes, K. L., 1997, "Quasi-steady state thermal resistance of a flexible copper-water heat pipe subjected to transient acceleration loading," Journal of Thermophysics and Heat Transfer, 11 (2):306-309.

http://dx.doi.org/10.2514/2.6239

Tohru Kishimoto, 1994, "Flexible-heat-pipe cooling for high-power devices," The International Journal of Microcircuits and Electronic Packaging, 17, (2):107.

Vadgama, B. N., 2004, "Experimental investigation of heat pipes with micro-fibrous metal felt wick and R134a working fluid," Masters' Thesis, Auburn University, Auburn, AL.

Williams, R. R. and Harris, D. K., 2003, "Cross-Plane and In-Plane Porous Properties Measurements of Thin Metal Felts: Applications in Heat Pipes," Experimental Thermal and Fluid Science, 27:227-235. http://dx.doi.org/10.1016/S0894-1777(02)00223-6

Williams, R. R. and Harris, D. K., 2005, "Wick Performance Characterization of Step-Graded Microfibrous Metal Felts," International Journal of Heat and Mass Transfer, 48 (2):293-305. http://dx.doi.org/10.1016/j.ijheatmasstransfer.2004.08.024

Wright, J. P., Brennan, P. J. and McCreight, C. R., 1976, "Development and test of two flexible cryogenic heat pipes (for spacecraft instrument cooling)," AIAA 11th Thermophysics Conference, San Diego, CA.

Zelenov, I. A., Zuev, V. G. and Poskonin, U. A., 1996, "Flexible heat pipes, construction special features and test results," ESA International Conference on Spacecraft Structures, Materials and Mechanical Testing, pp. 1381-1384, Noordwijk, Netherlands. 